\title{
Thrombosis of Bilateral Renal Veins, Inferior Vena Cava, and Superior Sagittal Sinus with Adrenal Hemorrhage in a Neonate
}

\author{
Guruprasad Peruri ${ }^{1}$, Suresh K Angurana ${ }^{2}$, Renu Suthar ${ }^{3}$, Venkataseshan $^{4}$, Vichithra Mohandoss ${ }^{5}$, Anmol Bhatia ${ }^{6}$
}

\begin{abstract}
We report a preterm male neonate with thrombosis of bilateral renal veins, infra-hepatic inferior vena cava, and superior sagittal sinus as well as left adrenal hemorrhage, which has been seldom reported in the literature. He was managed with appropriate antibiotics, enoxaparin, and supportive care which lead to resolution of thrombosis and normal renal function.

Keywords: Adrenal hemorrhage, Renal veins, Thrombosis.

Journal of Postgraduate Medicine, Education and Research (2019): 10.5005/jp-journals-10028-1320
\end{abstract}

\section{INTRODUCTION}

$\mathrm{N}$ eonates are more predisposed to thrombosis than older children because of low levels of anticoagulants (antithrombin III, protein C and S) and fibrinolytic component (plasminogen). ${ }^{1,2}$ Risk factors for thrombosis in neonates include vascular catheters, birth asphyxia, dehydration, sepsis, acidosis, polycythemia, gestational diabetes mellitus (GDM), cyanotic heart diseases, inherited thrombophilia (deficiency of protein $C$, protein $S$, and antithrombin III), and acquired thrombophilia [placental transfer of antiphospholipid antibodies (APLA) and maternal autoimmune disorders. ${ }^{1,3,4}$ Renal vein thrombosis (RVT) is the commonest noncatheter related thrombosis in neonates ${ }^{2,3}$ and can lead to longterm renal impairment. Cerebral sinovenous thrombosis (CSVT) though rare in neonates can lead to morbidities like seizures, cerebral palsy, and cognitive impairment.

We report a preterm neonate born to mother with GDM who presented in the early neonatal period with extensive thrombosis of bilateral renal veins, inferior vena cava (IVC) and superior sagittal sinus with adrenal hemorrhage. Treatment with enoxaparin leads to complete resolution of thrombosis.

\section{CASE RePORT}

A 3-day-male neonate born to primigravida at 36 weeks of gestation (birth weight $2.5 \mathrm{~kg}$ ) presented with hematuria and multiple seizures. Mother had a history of GDM and leaking per vaginum for 48 hours before delivery. He was admitted to a local hospital for 2 days and received intravenous antibiotics, fluids and vasoactive drugs, glucose infusion, and phenobarbitone.

Examination revealed normal vitals, pallor, pedal edema, encephalopathy, bimanually palpable and ballotable left flank mass, and dark colored urine.Investigations revealed blood glucose 98 $\mathrm{mg} \%$, hemoglobin $9.5 \mathrm{gm} \%$, TLC 9600/ $\mathrm{mm}^{3}$, platelet count 75,000/ $\mathrm{mm}^{3}$, PT 23 seconds, APTT 45 seconds, PTI 60\%, INR 2.13, fibrinogen 1.95g/L, D-dimers $7970 \mathrm{ng} / \mathrm{mL}$, sodium $138 \mathrm{meq} / \mathrm{L}$, potassium 5.1 meq/L, urea $54 \mathrm{mg} \%$, creatinine $1.4 \mathrm{mg} \%$, and multiple RBCs on urine examination. Blood culture grew Staphylococcus epidermidis. Abdominal ultrasonography and Doppler revealed enlarged kidneys (right $5.1 \mathrm{~cm}$ and left $5.3 \mathrm{~cm}$ ) with loss of corticomedullary differentiation, thrombus in bilateral renal veins extending into infra-hepatic IVC, and left adrenal hemorrhage. Contrast-enhanced computed tomography (CECT) abdomen showed thrombosis of bilateral renal veins and IVC with left adrenal hemorrhage \begin{tabular}{l}
\hline \hline${ }^{1}$ Senior Resident, ${ }^{2,3,6}$ Assistant Professor, ${ }^{4}$ Additional Professor, \\
${ }^{5}$ Junior Resident \\
${ }^{1-5}$ Department of Pediatrics, Postgraduate Institute of Medical Education \\
and Research, Chandigarh, India \\
${ }^{6}$ Department of Radiodiagnosis and Imaging, Lucknow, Uttar Pradesh,
\end{tabular} India

Corresponding Author: Suresh K Angurana, Assistant Professor, Department of Pediatrics, Postgraduate Institute of Medical Education and Research, Chandigarh, India, Phone: +919855373969, e-mail: sureshangurana@gmail.com

How to cite this article: Peruri G, Angurana SK, Suthar R, Venkataseshan, Mohandoss V, Bhatia A. Thrombosis of Bilateral Renal Veins, Inferior Vena Cava, and Superior Sagittal Sinus with Adrenal Hemorrhage in a Neonate. J Postgrad Med Edu Res 2019;53(2):89-90.

Source of support: Nil

Conflict of interest: None

(Figs $1 \mathrm{~A}$ and $\mathrm{B}$ ). CECT head revealed superior sagittal sinus thrombosis (Fig. 1C).

He received intravenous vancomycin for 10 days. Vasoactive drugs and glucose infusion were stopped by day 2 of admission. Low molecular weight heparin (LMWH) was started $(1.5 \mathrm{mg} / \mathrm{kg}$ BD subcutaneously). In next 3-5 days, there was improvement in coagulopathy, renal functions, hematuria, and encephalopathy. Magnetic resonance imaging (MRI) brain on day 15 of life revealed no CSVT. He was discharged on day 18 of life on LMWH. Serum homocysteine, ammonia, lactate, TMS and GCMS were normal. Maternal APLA workup, antinuclear antibodies, C3 and C4 were negative.

At 3 months of age, serum homocysteine was $6 \mu \mathrm{mol} / \mathrm{L}$ (normal: 4.2-12.8 $\mu \mathrm{mol} / \mathrm{L}$ ), protein C 48\%, and protein S 78\%; and negative anticardiolipin, anti-glycoprotein $1 \mathrm{~b}$ antibodies, lupus anticoagulant, and factor V Leiden mutation. Ultrasonography showed resolution of thrombus and enoxaparin was stopped. At 6 months of age, he had normal growth and development, and renal functions. The etiology considered for extensive thrombosis was multifactorial including maternal GDM, prematurity, and sepsis.

\section{Discussion}

Although RVT and CSVT in neonates are well documented in the literature, the coexistent thrombosis of renal veins, IVC, and

(c) The Author(s). 2019 Open Access This article is distributed under the terms of the Creative Commons Attribution 4.0 International License (https://creativecommons. org/licenses/by-nc/4.0/), which permits unrestricted use, distribution, and non-commercial reproduction in any medium, provided you give appropriate credit to the original author(s) and the source, provide a link to the Creative Commons license, and indicate if changes were made. The Creative Commons Public Domain Dedication waiver (http://creativecommons.org/publicdomain/zero/1.0/) applies to the data made available in this article, unless otherwise stated. 

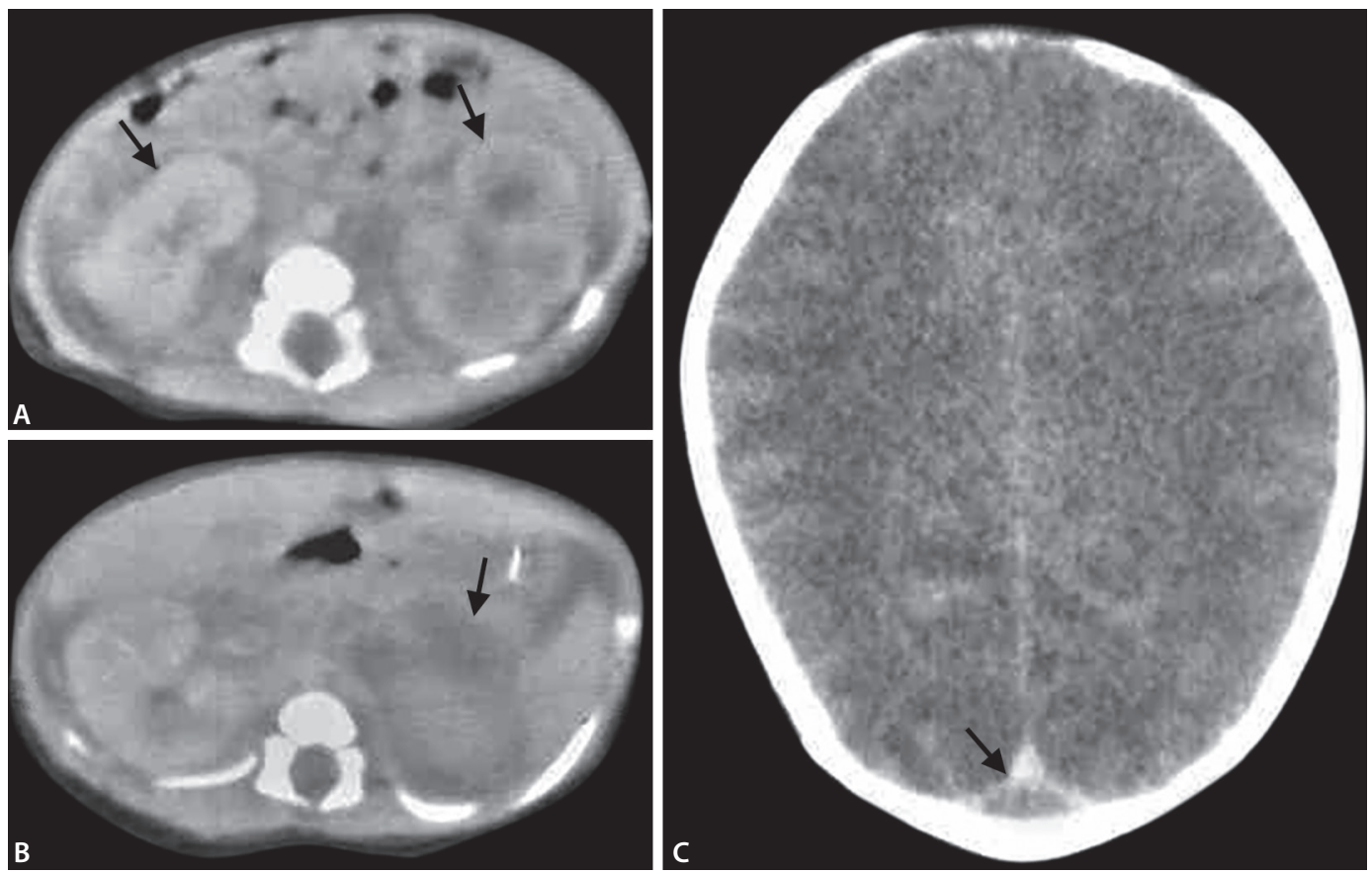

Figs $1 \mathrm{~A}$ to $\mathrm{C}$ : CECT abdomen axial images showing $(\mathrm{A})$ reduced nephrographic density of bilateral kidneys which were more marked on the left side (arrows) with (B) a hypodense mass lesion in left suprarenal fossa (arrow) from which left adrenal gland was not separately visualized. CECT axial image of head showing (C) a triangular hypodense filling defect in the posterior part of the superior sagittal sinus (arrow) suggestive of thrombus

superior sagittal sinus with adrenal hemorrhage is seldom reported in the literature. RVT accounts for $10-20 \%$ of venous thrombosis in neonates ${ }^{3}$ and $45-65 \%$ of cases are associated with inherited thrombophilia. RVT is more common in males, preterm neonates, and large for gestational age babies. Majority of neonatal RVT are unilateral with left preponderance, and bilateral in about $25 \%$ of cases. ${ }^{2}$ The thrombus may extend into IVC in $40-50 \%$ of cases and $15 \%$ may have adrenal hemorrhage. ${ }^{3-6}$ Only $10-15 \%$ had classical triad palpable flank mass, hematuria, and renal failure. ${ }^{1}$ The usual time of presentation is within the first 3 days of life, as in index case. Pohl et al. ${ }^{7}$ reported a 3-week neonate with bilateral RVT and CSVT due to heterozygous factor $V$ mutation with a complete resolution on heparin therapy. Klinge et al. $^{8}$ reported a neonate with bilateral RVT and CSVT due to heterozygous activated protein $C$ resistance who was treated with selective thrombolysis.

The treatment of thrombosis in neonates depends on the extent of involvement and organ dysfunction and associated hemorrhage. ${ }^{1-3,9}$ Supportive treatment, anticoagulation with LMWH or UFH for 3-6 months, and rarely thrombolysis are suggestive treatment modalities. ${ }^{3,9}$ Anticoagulation has been shown to improve survival remarkably to $85-95 \%$ and prevents renal atrophy in $65-70 \%$ of cases. ${ }^{9}$

Though the mortality in neonatal RVT is $<5 \%,{ }^{3}$ the long term morbidity is significant including hypertension, tubular dysfunction, renal atrophy, and chronic kidney disease. ${ }^{3}$ Poor prognosis is related to the extent of kidney damage, size $(>6 \mathrm{~cm})$, and perfusion. ${ }^{10}$

\section{Conclusion}

Extensive thrombosis involving bilateral renal veins, IVC, and superior sagittal sinus with adrenal hemorrhage is rare in neonates. Early diagnosis and treatment with anticoagulants can improve outcome in neonates with extensive thrombosis.

\section{References}

1. Resontoc LP, Yap HK. Renal vascular thrombosis in the newborn. Pediatr Nephrol 2016;31:907-915.

2. Sirachainan $N$, Limrungsikul $A$, Chuansumrit $A$, et al. Incidences, risk factors and outcomes of neonatal thromboembolism. J Matern Fetal Neonatal Med 2018;31:347-351.

3. Bidadi B, Nageswara Rao AA, Kaur D, et al. Neonatal renal vein thrombosis: role of anticoagulation and thrombolysis-an institutional review. Pediatr Hematol Oncol. 2016;33:59-66.

4. Sandal G, Arikan E, Kuybulu AE, et al. Unilateral Renal Vein Thrombosis and Adrenal Hemorrhage in A Newborn with Homozygous Factor V Leiden and Heterozygous Of MTHFR-677T, MTHFR-1298C Gene Mutations. Indian J Hematol Blood Transfus 2014;30(Suppl 1): 294-298.

5. Alabsi SY, Layland T. Adrenal Hemorrhage in Neonates: Unusual Presentation. Neonatal Netw 2015;34:220-226.

6. Tran-Minh VA, Genin G, Pracros JP, et al. Coexisting calcified inferior vena cava thrombus and adrenal hemorrhage in the neonate: report of three cases. J Clin Ultrasound 1994;22:103-108.

7. Pohl M, ZimmerhackI LB, Heinen F, et al .Bilateral renal vein thrombosis and venous sinus thrombosis in a neonate with factor $\mathrm{V}$ mutation (FV Leiden). J Pediatr 1998;132:159-161.

8. Klinge J, Scharf J, Rupprecht $\mathrm{T}$, et al. Selective thrombolysis in a newborn with bilateral renal venous and cerebral thrombosis and heterozygous APC resistance. Nephrol Dial Transplant 1998;13: 3205-3207.

9. Monagle P, Chan AKC, Goldenberg NA, et al. Antithrombotic therapy in neonates and children: Antithrombotic Therapy and Prevention of Thrombosis, 9th ed: American College of Chest Physicians Evidence-Based Clinical Practice Guidelines. Chest 2012;141: e737S-e801S.

10. Winyard PJ, Bharucha T, De Bruyn R, et al. Perinatal renal venous thrombosis: presenting renal length predicts outcome. Arch Dis Child Fetal Neonatal Ed 2006;91:F273-278. 